\title{
RESEARCH
}

Open Access

\section{Potential of resveratrol in enrichment of neural progenitor-like cell induction of human stem cells from apical papilla}

\author{
Anupong Songsaad ${ }^{1}$, Thanasup Gonmanee ${ }^{2}$, Nisarat Ruangsawasdi ${ }^{3}$, Chareerut Phruksaniyom $^{3}$ and
} Charoensri Thonabulsombat ${ }^{1 *}$ (D)

\begin{abstract}
Introduction: Stem cell transplantation of exogenous neural progenitor cells (NPCs) derived from mesenchymal stem cells (MSCs) has emerged as a promising approach for neurodegenerative disease. Human stem cells from apical papilla (hSCAPs) are derived from migratory neural crest stem cells and exhibit a potential of neuronal differentiation. However, their neuronal differentiation is low and unpredictable. Resveratrol has been described as a sirtuin 1 (SIRT1) activator which plays an important role in enhancing neuronal differentiation. In this study, we investigate the potential of resveratrol as an enhancer on neuronal differentiation through NPCs induction of hSCAPs.

Methods: Stem cells were isolated from human apical papilla and characterized as MSCs. The cellular toxicity of resveratrol treatment to the characterized hSCAPs was investigated by MTT assay. The non-cellular toxicity concentrations of resveratrol were assessed with various pre-treatment times to select the optimal condition that highly expressed the neural progenitor gene, NES. Consequently, the optimal condition of resveratrol pre-treatment was synergistically performed with a neuronal induction medium to trigger neuronal differentiation. The differentiated cells were visualized, the genes profiling was quantified, and the percentage of neuronal differentiation was calculated. Moreover, the intracellular calcium oscillation was demonstrated.
\end{abstract}

Results: The cellular toxicity of resveratrol was not observed for up to $50 \mu \mathrm{M}$ for $12 \mathrm{~h}$. Interestingly, hSCAPs pre-treated with $10 \mu \mathrm{M}$ resveratrol for $12 \mathrm{~h}$ (RSV-hSCAPs) significantly expressed NES, which is determined as the optimal condition. Under neuronal induction, both of hSCAPs and RSV-hSCAPs were differentiated (d-hSCAPs and RSV-d-hSCAPs) as they exhibited neuronal-like appearances with Nissl substance staining. The highest expression of NES and SOX1 was observed in RSV-dhSCAPs. Additionally, the percentage of neuronal differentiation of RSV-d-hSCAPs was significantly higher than d-hSCAPs for 4 times. Importantly, the neuronal-like cells exhibited slightly increasing pattern of calcium intensity.

Conclusion: This study demonstrated that pre-treatment of resveratrol strongly induces neural progenitor marker gene expression which synergistically enhances neural progenitor-like cells' induction with neuronal induction medium.

Keywords: Resveratrol, Neural progenitor-like cells, Human stem cells from apical papilla

\footnotetext{
* Correspondence: charoensri.tho@mahidol.ac.th

${ }^{1}$ Department of Anatomy, Faculty of Science, Mahidol University, 272 RAMA

VI Road, Ratchathewi, Bangkok 10400, Thailand

Full list of author information is available at the end of the article
}

\section{$\triangle B M C$}

(C) The Author(s). 2020 Open Access This article is licensed under a Creative Commons Attribution 4.0 International License, which permits use, sharing, adaptation, distribution and reproduction in any medium or format, as long as you give appropriate credit to the original author(s) and the source, provide a link to the Creative Commons licence, and indicate if changes were made. The images or other third party material in this article are included in the article's Creative Commons licence, unless indicated otherwise in a credit line to the material. If material is not included in the article's Creative Commons licence and your intended use is not permitted by statutory regulation or exceeds the permitted use, you will need to obtain permission directly from the copyright holder. To view a copy of this licence, visit http://creativecommons.org/licenses/by/4.0/. The Creative Commons Public Domain Dedication waiver (http://creativecommons.org/publicdomain/zero/1.0/) applies to the data made available in this article, unless otherwise stated in a credit line to the data. 


\section{Introduction}

The neurological disorders of the central nervous system (CNS) account for more than $10 \%$ of death and new causes of permanent disability. The most common neurological disorders of CNS consist of Parkinson's disease, Alzheimer's disease, stroke, and traumatic brain injuries [1]. The cardinal characteristic that these neurological disorders have been defined by is loss of neurons and the corresponding loss of function and disabilities [2]. Adult neurogenesis is the process of generating new neurons from NPCs [3]. Unfortunately, endogenous repairing of affected CNS via the NPCs is restricted and limited [4]. To improve the quality of life of patients who are suffering from neurological disorders, a replacement of degenerated neurons with exogenous NPCs could be a potential treatment to regenerate the damaged CNS.

Human stem cells from apical papilla were discovered by Sonoyama W. in 2008 [5]. As the name implies, the hSCAPs are localized at the apex part (apical papilla) of the developing tooth which contains the stem cells and have characterized as MSCs [6]. According to the origin, the hSCAPs represent early stem cell populations that exhibit superior stem cell properties, including self-renewal and differentiation potency, to the other dental-derived stem cells (DSCs), which are isolated from a mature tissue [7]. MSCs can be characterized by differentiation into at least 3 specialized lineages: adipocytes, osteocytes, and chondrocytes [8]. Moreover, neuronal cells can be generated from MSCs by administration of extrinsic factors in the neuronal induction medium as demonstrated in several MSCs-derived tissues, including the adipose tissue [9], bone marrow [10], umbilical cord [11], cord blood [12], periodontal ligament [13], and both deciduous and permanent teeth [14]. Therefore, MSCs are an efficient stem cell source for neuronal differentiation. However, the ability of neuronal differentiation of MSCs has some limitations involving a low percentage of differentiation and unpredictability of differentiated cell type [15]. Moreover, most of the engrafted cells die within a week of transplantation, and only a few engrafted cells successfully integrated into the injured area [16].

Recently, medicinal plant-derived natural compounds have become of interest as alternative sources of new therapeutic agents for neurodegenerative disease. Moreover, they exert their potential effects by enhancing neuronal differentiation and adult neurogenesis [17]. Resveratrol (3,4',5-trihydroxy-trans-stilbene) is defined as a natural non-flavonoid polyphenol compound with a stilbene structure obtained from various plants including grapes, peanuts, pine trees, and berry plants [18]. Remarkably, resveratrol has been identified as a SIRT1 activator playing an important role in enhancing neuronal differentiation and neuroprotection [19]. Previous studies have demonstrated the potential of SIRT1 activator resveratrol in inducing neuronal differentiation and structural morphological change of MSCs derived from the bone marrow [20], umbilical cord [21], cord blood [12], and dental pulp [15] into the neuronal cells. Also, pre-treatment of resveratrol to MSCs at an optimal condition significantly promotes NPCs gene expression [20]. Despite recent progress, enhancing NPCs induction of hSCAPs by resveratrol has not yet been investigated.

In this study, we demonstrated the potential effect of resveratrol on neuronal differentiation using the optimal condition that directly drives neuronal differentiation into neural progenitor-like cells of hSCAPs.

\section{Methods}

\section{Tooth sample collection}

Human impacted third molars $(n=7)$ were collected from Thai patients (15-20 years) at the Faculty of Dentistry, Mahidol University, Thailand. The ethical consideration and research protocol were approved by the Ethics Committee on Human Rights Related to Human Experimentation of Faculty of Dentistry/Faculty of Pharmacy, Mahidol University (COE. No. MU-DT/PY-IRB 2019/027.2405). The inclusion criteria of the teeth consist of the presence of apical papilla tissue, caries-free, and no sign of pulp necrosis, trauma, or periodontal disease.

\section{Cell isolation and culture}

The isolation of hSCAPs was performed by the enzymatic-disaggregation method as previously described [6]. Briefly, the teeth were collected in a proliferating medium consisting of Alpha Minimum Essential Medium ( $\alpha$ MEM, Gibco, Life Technologies, Grand Island, NY, USA), supplemented with $10 \%$ fetal bovine serum (FBS, Gibco, Life Technologies), $100 \mathrm{U} / \mathrm{mL}$ penicillin, and $100 \mu \mathrm{M} / \mathrm{mL}$ streptomycin (Gibco, Life Technologies), and washed with $0.1 \mathrm{M}$ phosphate buffer saline (PBS, SigmaAldrich, St. Louis, MO, USA). Following teeth extraction, the apical papilla tissue was separated, dissected into smaller pieces, and digested with a cocktail of $3 \mathrm{mg} / \mathrm{mL}$ collagenase type I (Worthington, Lakewood, NJ, USA) and $4 \mathrm{mg} / \mathrm{mL}$ dispase II (Sigma-Aldrich) at $37^{\circ} \mathrm{C}$ for $1 \mathrm{~h}$. The digested tissue was filtered through $70 \mu \mathrm{m}$ cell strainer (Falcon $^{\mathrm{mw}}$, Fisher Scientific, Waltham, MA, USA), seeded into a cell culture vessel $\left(\mathrm{T}-75 \mathrm{~cm}^{2}\right.$ flask, Nunct $\mathrm{c}^{\mathrm{m}}$, Thermo Scientific, Waltham, MA, USA), and cultured in the proliferating medium at $37^{\circ} \mathrm{C}, 5 \% \mathrm{CO}_{2}$, and $95 \%$ humidity incubator. The medium was changed every 2 days until confluence was achieved. Then, the cells were subculture to expand the cell population. Cells at passages 2-6 were used in this study.

\section{Cell surface molecule marker analysis}

The uncharacterized cells $\left(1 \times 10^{6}\right.$ cells $)$ were harvested and the cell surface antigen molecules were analyzed by 
BD FACS Canto Flow cytometer (BD Biosciences, San Jose, CA, USA). The cells were detected for MSCs specific markers using antibodies as follows: anti-human CD73 (APC/Cy7) (Biolegend, San Diego, CA, USA), anti-human CD90 (PE) (Biolegend), anti-human CD105 (Alexa Flour ${ }^{\circ}$ 488) (Biolegend), and anti-human CD146 (PerCP/Cy5.5) (Biolegend). An antibody against hematopoietic stem cell marker, anti-human CD34 (APC) (Biolegend), was used as a negative control. The level of cell surface antigen molecules expression was analyzed using the BD FACSDiva ${ }^{\text {ma }}$ software (BD Biosciences).

\section{Colony-forming unit fibroblast}

The uncharacterized cells were seeded in triplicate into 6-well plates (Nunc ${ }^{\mathrm{Tm}}$, Thermo Scientific) at a density of 500 cells/well and cultured in the proliferating medium for 12 days. The medium was changed every 2 days. The colonies of these cells were visualized by Giemsa staining and captured by the Compact Cell Culture Microscope, CKX3 (Olympus, Hamburg, Germany).

\section{Osteogenic differentiation}

The uncharacterized cells were seeded in 24-well plates (Nunc $^{\mathrm{Tx}}$, Thermo Scientific) at a density of $2 \times 10^{4}$ cells/ well and cultured in the proliferating medium until reaching $80 \%$ confluence. Osteogenic differentiation was induced by culturing for 4 weeks in an osteogenic induction medium consisting of $0.1 \mu \mathrm{M}$ dexamethasone (Sigma-Aldrich), $50 \mu \mathrm{g} / \mathrm{mL}$ ascorbate-2-phosphate (Sigma-Aldrich), $10 \mathrm{mM} \beta$-glycerophosphate (Sigma-Aldrich) in $\alpha \mathrm{MEM}$, $10 \% \mathrm{FBS}, 100 \mathrm{U} / \mathrm{mL}$ penicillin, and $100 \mu \mathrm{M} / \mathrm{mL}$ streptomycin. The medium was changed every 2 days. The calcification of an extracellular matrix was observed with Alizarin red staining and captured by the Compact Cell Culture Microscope, CKX3 (Olympus).

\section{Adipogenic differentiation}

The uncharacterized cells were seeded in 24-well plates (Nunc $^{\mathrm{Tm}}$, Thermo Scientific) at a density of $2 \times 10^{4}$ cells/ well and cultured in the proliferating medium until reaching $100 \%$ confluence. Adipogenic differentiation was induced by culturing for 6 weeks in an adipogenic induction medium consisting of the proliferating medium supplemented with $1 \mu \mathrm{M}$ dexamethasone (Sigma-Aldrich), $50 \mu \mathrm{M}$ indomethacin (Sigma-Aldrich), $1 \mu \mathrm{g} / \mathrm{mL}$ insulin (Sigma-Aldrich), and 0.5 mM 3-isobutyl-1-methylxanthine (IBMX, Sigma-Aldrich). Oil Red O was stained to visualize lipid droplets and captured by the Compact Cell Culture Microscope, CKX3 (Olympus).

\section{Cell viability of resveratrol-treated hSCAPs}

The cell viability of resveratrol-treated hSCAPs was performed by the methylthiazolyldiphenyl-tetrazolium bromide (MTT, Sigma-Aldrich) assay. Resveratrol (trans3, 4', 5-trihydroxystibene; Sigma-Aldrich) was freshly prepared as a $100 \mu \mathrm{M}$ stock solution by diluting with $\alpha \mathrm{MEM}$, $100 \mathrm{U} / \mathrm{mL}$ penicillin, $100 \mu \mathrm{M} / \mathrm{mL}$ streptomycin, and maintained in dark condition. The characterized hSCAPs were seeded in 96-well plates (Nunc ${ }^{\text {tw }}$, Thermo Scientific) at a density of $1 \times 10^{4}$ cells/well. After $24 \mathrm{~h}$, the hSCAPs were treated with different concentrations of resveratrol $(0,5$, $10,15,25,50$, and $100 \mu \mathrm{M}$ ) for 6,12 , and $24 \mathrm{~h}$. Then, the MTT assay was performed. The MTT working solution $(0.5 \mathrm{mg} / \mathrm{mL})$ was added, and the plates were incubated for an additional $2 \mathrm{~h}$ at $37^{\circ} \mathrm{C}$. After centrifugation, the solution was replaced with dimethyl sulfoxide (DMSO, Fisher Scientific). The absorbance of each well at $570 \mathrm{~nm}$ and $690 \mathrm{~nm}$ was measured with a micro-plate reader (Epoch, Fisher Scientific, Waltham, MA, USA). The percentage of cell viability of hSCAPs in resveratrol treatments $\left(\mathrm{A}_{570^{-}}\right.$ $\mathrm{A}_{690}$ of experimental group $\times 100 / \mathrm{A}_{570}-\mathrm{A}_{690}$ of control group) $(n=5)$ and the $50 \%$ inhibitory concentration $\left(\mathrm{IC}_{50}\right)$ of resveratrol pre-treatment on hSCAPs were reported.

\section{Optimal condition of resveratrol pre-treatment}

The hSCAPs were seeded in 6-well plates at a density $1 \times 10^{5}$ cells/well. After $24 \mathrm{~h}$, the cells were incubated with different non-cellular toxicity concentrations of resveratrol for $12 \mathrm{~h}$, and qRT-PCR was performed to select the concentration of resveratrol that induced the highest NES expression of hSCAPs. Then, the concentration was used to assess NES expression at various incubation times $(1,6,12$, and $24 \mathrm{~h})$. The treatments were also investigated for morphological change with $\beta$-III tubulin immunocytochemistry staining. The hSCAPs treated with resveratrol at the concentration and incubation time that brought the highest NES expression will be termed "RSV-hSCAPs." The RSV-hSCAPs were validated the neuronal genes profiling with SOX1, PAX6, and immunofluorescences with Ki67, neurofilaments (NF), and were further induced into neuronal differentiation.

\section{Neuronal induction}

The hSCAPs were seeded on poly-d-lysine (Sigma-Aldrich) coated cover slips (Electron Microscopy Sciences, Hatfield, PA, USA) in 6-well plates at a density $1 \times$ $10^{5}$ cells/well and pre-incubated with the optimal condition of resveratrol (RSV-hSCAPs) or without resveratrol (hSCAPs). Then, both hSCAPs and RSV-hSCAPs were exposed to 2 phases of neuronal induction medium. First, the cells were incubated with Dulbecco's Modified Eagle Medium: Nutrient Mixture F-12 (Ham) (DMEM/ F-12, Gibco, Life Technologies) supplemented with 10\% FBS, $100 \mathrm{U} / \mathrm{mL}$ penicillin, $100 \mu \mathrm{M} / \mathrm{mL}$ streptomycin, 10 $\mathrm{ng} / \mathrm{mL}$ basic fibroblast growth factor (bFGF, Gibco Life Technologies), and $500 \mu \mathrm{M} \beta$-mercaptoethanol (SigmaAldrich) for $24 \mathrm{~h}$. After that, the cells were induced into 
a phase II neuronal induction medium which consisted of DMEM/F-12, $100 \mathrm{U} / \mathrm{mL}$ penicillin, $100 \mu \mathrm{M} /$ $\mathrm{mL}$ streptomycin, 2\% DMSO, and $100 \mu \mathrm{M}$ butylated hydroxyanisole (BHA, Sigma-Aldrich) for $6 \mathrm{~h}$. The negative control hSCAPs (crt-hSCAPs) was preincubated for $12 \mathrm{~h}$ with $\alpha \mathrm{MEM}, 100 \mathrm{U} / \mathrm{mL}$ penicillin, $100 \mu \mathrm{M} / \mathrm{mL}$ streptomycin, and then cultured with DMEM/F-12, $10 \%$ FBS, $100 \mathrm{U} / \mathrm{mL}$ penicillin, and $100 \mu \mathrm{M} / \mathrm{mL}$ streptomycin for $24 \mathrm{~h}$. The medium was then replaced with DMEM/F-12, $100 \mathrm{U} / \mathrm{mL}$ penicillin, and $100 \mu \mathrm{M} / \mathrm{mL}$ streptomycin for $6 \mathrm{~h}$.

\section{Immunocytochemistry}

The specimens were fixed in $4 \%$ paraformaldehyde (Sigma-Aldrich) in PBS at room temperature for $1 \mathrm{~h}$, followed by $20 \%$ ice-cold methanol (Sigma-Aldrich) in PBS for $5 \mathrm{~min}$, and then washed with PBS. Subsequently, the specimens were permeabilized with $0.5 \%$ Triton X100 (Sigma-Aldrich) in PBS overnight at $4{ }^{\circ} \mathrm{C}$ and blocked with $15 \%$ bovine serum albumin (BSA, SigmaAldrich) at $4{ }^{\circ} \mathrm{C}$ for $12 \mathrm{~h}$. The specimens were incubated overnight at $4{ }^{\circ} \mathrm{C}$ with anti-mouse Nestin antibody (Biolegend) at a dilution of 1: 500, anti-mouse $\beta$-III tubulin antibody (Biolegend) at a dilution of 1: 1000, anti-mouse Ki67 (Developmental Studies Hybridoma bank, Iowa City, IA, USA) at a dilution 1:100, and anti-mouse NF (Developmental Studies Hybridoma bank) at a dilution 1:100 which diluted with 5\% BSA in PBS with $0.05 \%$ Tween-20 (Sigma-Aldrich). Then, the specimens were conjugated with goat anti-mouse IgG highly crossadsorbed secondary antibody, Alexa Fluor plus 488 (Invitrogen, New York, NY, USA) at a dilution of 1: 1000 at room temperature for $4 \mathrm{~h}$. Nuclei were counterstained and mounted with ProLong ${ }^{\mathrm{Tm}}$ Diamond Antifade Mountant with DAPI (Invitrogen). The samples were visualized and captured by the Digital Fluorescence Microscope, BX53 (Olympus). The percentage of neuronal differentiation (the number of differentiated cells $\times$ $100 /$ total cells) was quantified using the ImageJ program $(\mathrm{NIH}$, Bethesda, MD, USA) by random counting $(n=5)$.

\section{Quantitative real-time reverse transcription polymerase chain reaction (qRT-PCR)}

Total RNA was extracted using the Nucleospin RNA plus kit (Macherey-Nagel, Bethlehem, PA, USA) and converted into cDNA using iScript RT Supermix (BioRad, Hercules, CA, USA). The qRT-PCR was performed using KAPA SYBR $^{\circ}$ FAST qPCR kits (Sigma-Aldrich) with CFX96 $6^{\text {m }}$ real-time PCR detection system (Bio-Rad). The qRT-PCR reaction conditions were $95^{\circ} \mathrm{C}$ for $3 \mathrm{~min}$, followed by 40 cycles of $95^{\circ} \mathrm{C}$ for $3 \mathrm{~s}$ and $52^{\circ} \mathrm{C}$ for $30 \mathrm{~s}$. The interesting primers (Integrated DNA Technologies, Gemini Singapore Science Park II, Singapore) used in this study are listed in Table 1 . The glyceraldehyde 3-
Table 1 Forward and reverse primers for qRT-PCR

\begin{tabular}{llll}
\hline Genes & Primers & Sequences (5'-3') $^{\prime}$ & References \\
\hline NES & Forward & CTGCTACCCTTGAGACACCTG & NM_006617.1 \\
& Reverse & GGGCTCTGATCTCTGCATCTAC & \\
MAP-2 & Forward & CGAAGCGCCAATGGATTCC & NM_001039538.1 \\
& Reverse & TGAACTATCCTGCAGACACCT & \\
TUBB3 & Forward & GGCCAAGGGTCACTACACG & NM_006086.3 \\
& Reverse & GCAGTCGCAGTTITCACACTC & \\
SOX1 & Forward & GTAAGGGACCCGGGGATG & NM_005986.3 \\
& Reverse & GGGGTCTTCCCTCCTCCT & \\
PAX6 & Forward & AACAGACACAGCCCTCACAAACA & NM_001368892.2 \\
& Reverse & CGGGAACTTGAACTGGAACTGAC & \\
GAPDH & Forward & CTGGGCTACACTGAGCACC & NM_001256799 \\
& Reverse & AAGTGGTCGTTGAGGGCAATG & \\
\hline
\end{tabular}

phosphate dehydrogenase (GAPDH) was used as an internal control, and the expression of interested genes was measured by $2^{-\Delta \Delta C t}$ method [22].

\section{Cresyl violet staining}

The specimens were fixed in $4 \%$ paraformaldehyde at room temperature for $60 \mathrm{~min}$, and then washed with PBS for 5 min and double distill water $\left(\mathrm{ddH}_{2} \mathrm{O}\right)$ for 1 min. Subsequently, the specimens were incubated with Cresyl Violet Acetate working solution (Electron Microscopy Sciences) at dark condition for $60 \mathrm{~min}$. Then, the specimens were washed with $\mathrm{ddH}_{2} \mathrm{O}$, followed by serial dehydration of $90 \%, 95 \%$, and $100 \%$ ethanol respectively. Cell imaging was captured by the Compact Cell Culture Microscope, CKX3 (Olympus).

\section{Intracellular calcium oscillation}

In order to identify potential of neuronal differentiation, we evaluated calcium influx which is an indicator for neurotransmitter transmission. The intracellular calcium assessment was described in previous study [23]. The specimens were incubated with $3 \mu \mathrm{M}$ Fluo-3 $\mathrm{AM}$ (Invitrogen) and $0.08 \%$ pluronic acid (Invitrogen) in DMEM/F-12, $100 \mathrm{U} / \mathrm{mL}$ penicillin, and $100 \mu \mathrm{M} / \mathrm{mL}$ streptomycin at $37^{\circ} \mathrm{C}$ for $60 \mathrm{~min}$. Subsequently, the specimens were washed with DMEM/F-12, $100 \mathrm{U} / \mathrm{mL}$ penicillin, $100 \mu \mathrm{M} / \mathrm{mL}$ streptomycin, and PBS. The specimens were maintained in Tyrode's solution $(5 \mathrm{mM}$ $\mathrm{KCl}, 129 \mathrm{mM} \mathrm{NaCl}, 2 \mathrm{mM} \mathrm{CaCl}, 1 \mathrm{mM} \mathrm{MgCl}, 30 \mathrm{mM}$ glucose, and $25 \mathrm{mM}$ HEPES, pH 7.4) (all from SigmaAldrich). The neurotransmitter releasing ability of differentiated cells was simulated with $50 \mathrm{mM} \mathrm{KCI}$. The intensity of calcium was recorded time-lapse at excitation $506 \mathrm{~nm}$ for $3 \mathrm{~min}$ by the live-cell fluorescence microscope, IX83XDC (Olympus) and interpreted using the ImageJ program $(\mathrm{NIH})$. 


\section{Statistical analysis}

The individual experiment was repeated 3 times. The data were expressed as the mean \pm standard error of mean (SEM), the difference between the experimental groups and the control group were compared using Tukey's Multiple Comparison Test via GraphPad Prism version 5.00.288 (San Diego, CA, USA). The differences with " $p$ value $<0.05$ and $* * * p$ value $<0.001$ were considered significant.

\section{Results}

\section{Characterization of hSCAPs}

Firstly, the isolated cells from human apical papilla tissue presented the typical fibroblast and spindle-like shape morphology in plastic adherent culture (Fig. 1a). Secondly, the cell surface antigen molecule analysis via flow cytometry demonstrated the cells highly expressed MSCs markers, CD73 (99.8\%), CD90 (99.8\%), CD105 (83.8\%), CD146 (31.3\%), and negatively expressed CD34 (0.2\%). The isolated cells that co-expressed CD73+, CD90+, CD105+, CD146+, and CD34- were a major population (70.1\%) (Fig. 1b). The cells effectively formed colonies indicating the self-renewal ability (Fig. 1c). In evaluating the neural crest derivative origin, the immunofluorescence reveals the Nestin expression of the isolated cells (Fig. 1d). Multipotential differentiation properties were shown by osteogenic and adipogenic induction. The cells produced calcified nodules (Fig. 1e) and lipid droplets (Fig. 1f) as revealed by Alizarin red and Oil Red O staining, respectively. These indicated that the cells were able to differentiate into osteocytes and adipocytes. Taken together, the isolated cells exhibited MSCs properties, verified as hSCAPs.

\section{The cellular toxicity of resveratrol on hSCAPs}

To evaluate the toxicity of resveratrol on hSCAP viability, the hSCAPs were incubated with $0-100 \mu \mathrm{M}$ of resveratrol for 6,12 , and $24 \mathrm{~h}$. The viability of the cells did not observe cytotoxicity at any concentrations of resveratrol treatment for $6 \mathrm{~h}$ (Fig. 2a). In contrast, the cellular viability significantly decreased at $12 \mathrm{~h}$ in $100 \mu \mathrm{M}$ (Fig. 2b) and $24 \mathrm{~h}$ in $25 \mu \mathrm{M}$ resveratrol treatment (Fig. 2c), compared to the control group. Additionally, the $\mathrm{IC}_{50}$ of resveratrol treatment on hSCAPs were shown as $3380 \mathrm{mM}(6 \mathrm{~h}), 1501 \mu \mathrm{M}(12 \mathrm{~h})$, and $73.33 \mu \mathrm{M}(24 \mathrm{~h})$ (Fig. 2d). As a result, the concentration of resveratrol ranging to $0-50 \mu \mathrm{M}$ for $12 \mathrm{~h}$ pre-treatment was chosen for use in the next experiment.

\section{Optimal condition of resveratrol pre-treatment}

To evaluate the effect of resveratrol on enhancing neuronal differentiation of hSCAPs, the cells were incubated with $0-50 \mu \mathrm{M}$ of resveratrol for $12 \mathrm{~h}$. We hypothesized that resveratrol pre-treatment would promote the

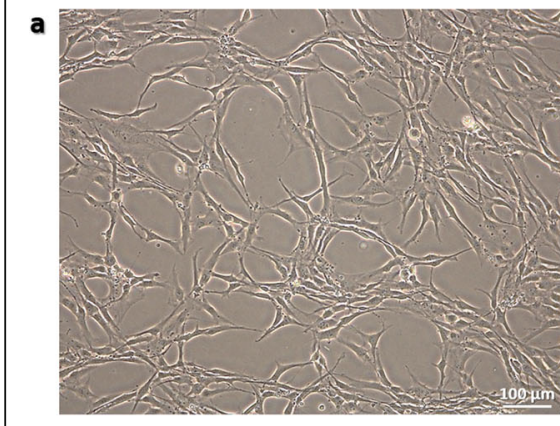

b

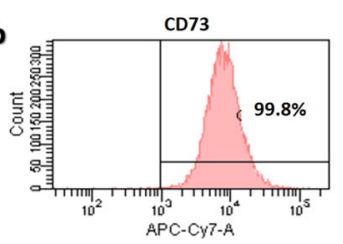

CD146

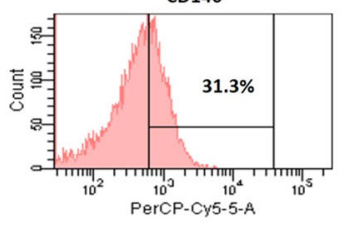

C

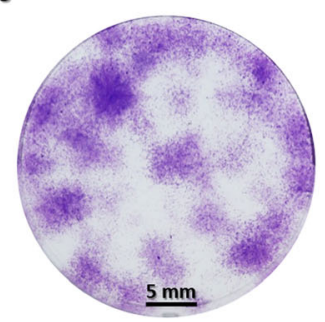

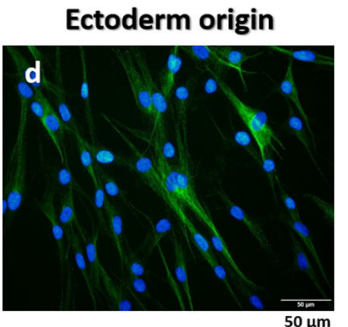

(Nestin staining)
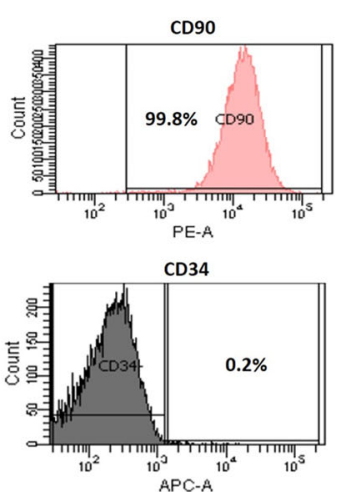

Osteogenic (4 weeks)

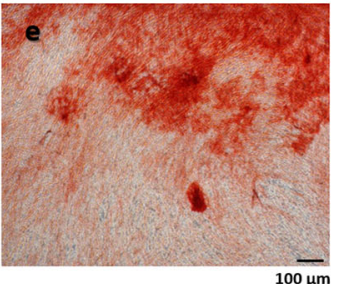

(Alizarin red staining)

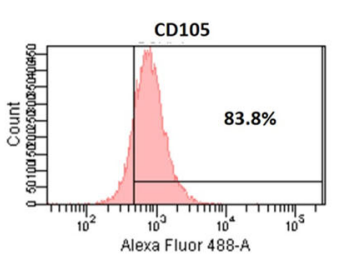

CD34-CD73+CD90+CD105+CD146+

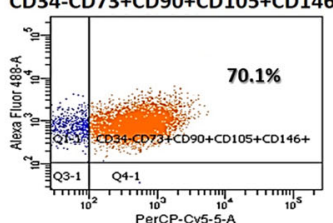

Adipogenic (6 weeks)

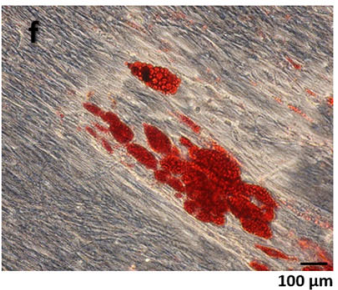

(Oil Red O staining)

Fig. 1 Characterization of hSCAPs. a Isolated cells present the typical fibroblast and spindle-like-shaped morphology. $\mathbf{b}$ The cells are positive for CD73, CD90, CD105, and CD146 but negative for CD34. The amount of isolated cells that expressed these markers (CD73+, CD90+, CD105+, CD146+, and (D34-) are highly expressed. c The cells efficiently form colonies. $\mathbf{d}$ The cells reveal the neural crest derivative origin with nesting staining. e Osteogenic differentiation was demonstrated with Alizarin red staining of calcified nodule. $\mathbf{f}$ Adipogenic differentiation was revealed with lipid droplets stained by Oil Red O. Scale bars: $\mathbf{a}$, e, and $\mathbf{f}=100 \mu \mathrm{m}, \mathbf{c}=5 \mathrm{~mm}$, and $\mathbf{d}=50 \mu \mathrm{m}$ 


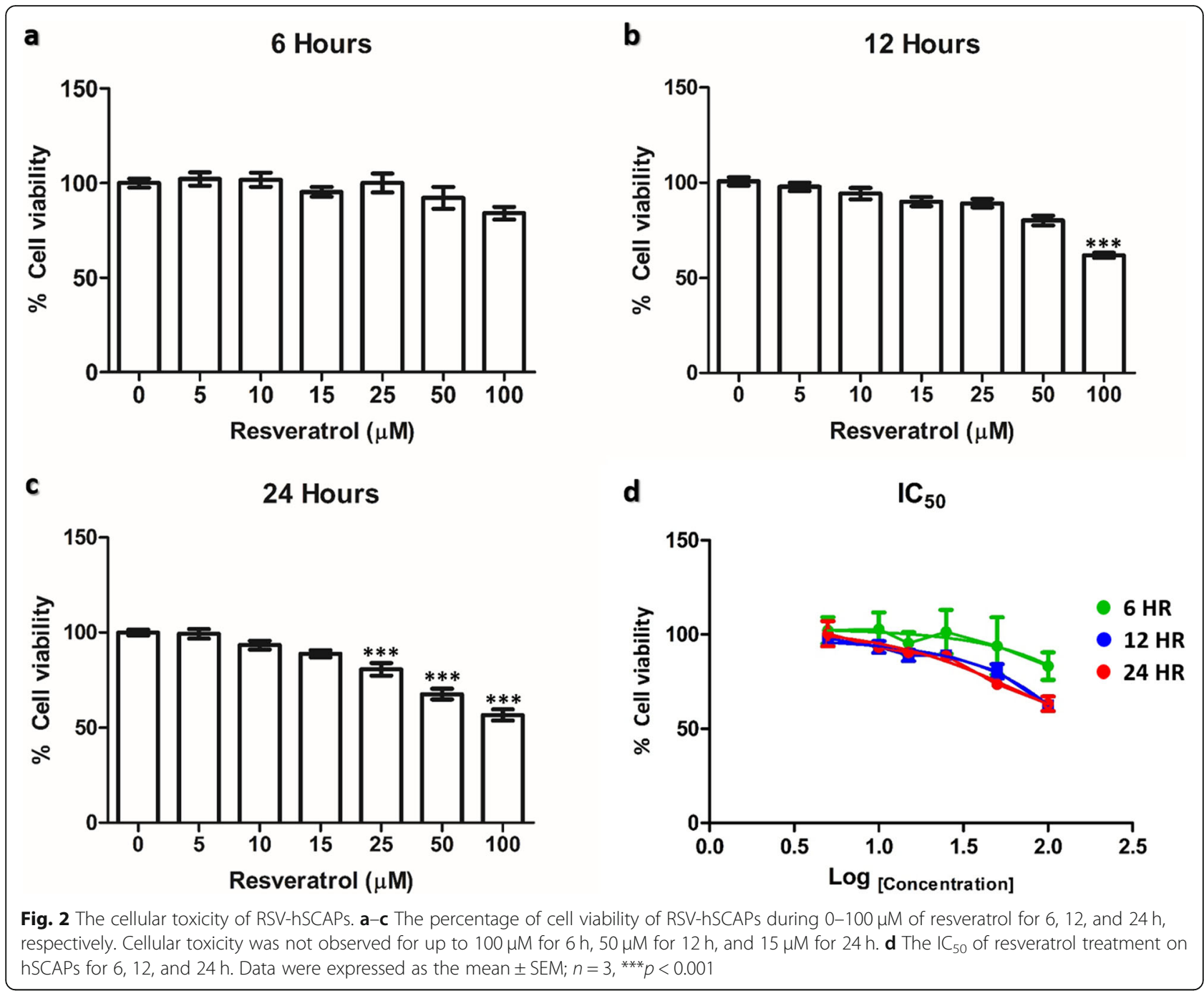

expression of NPCs gene, NES. The qRT-PCR demonstrated that the NES expression significantly increased at $10 \mu \mathrm{M}$ resveratrol pre-treatment, compared to control. However, the expression significantly decreased at $50 \mu \mathrm{M}$. (Fig. 3a). To determine optimal pre-treatment time, the hSCAPs treated with $10 \mu \mathrm{M}$ resveratrol were investigated for $N E S$ expression at various incubation times: $1,6,12$, and $24 \mathrm{~h}$. The NES expression was significantly highest at $12 \mathrm{~h}$ and dropped at $24 \mathrm{~h}$ of pretreatment time (Fig. 3b). The expression of other neural progenitor genes (SOX1 and PAX6) of hSCAPs treated with $10 \mu \mathrm{M}$ resveratrol for $12 \mathrm{~h}$ were not significantly different, compared to control (Fig. 3c). Moreover, the $\beta$-III tubulin immunofluorescence staining revealed that all of the resveratrol-treated hSCAPs ranging from 0 to $50 \mu \mathrm{M}$ for $12 \mathrm{~h}$ (Fig. 3d) and $10 \mu \mathrm{M}$ for $1,6,12$, and $24 \mathrm{~h}$ of pre-treatment times (Fig. 3e) exhibited morphology as the typical fibroblast and spindle-like shape, which was similar to the control and the primary hSCAPs (Fig. 1a).
Interestingly, the hSCAPs treated with $10 \mu \mathrm{M}$ resveratrol for $12 \mathrm{~h}$ positively expressed Nestin, $\beta$-III tubulin, and Ki67 (proliferative marker) and negatively expressed neurofilament marker (Fig. 3f) suggesting that the resveratrol-treated hSCAPs have not yet differentiated into neuronal cells but resveratrol treatment activated neural progenitor gene expression (NES). Therefore, the pre-treatment of resveratrol at $10 \mu \mathrm{M}$ for $12 \mathrm{~h}$ was determined as the optimal condition and referred to as RSVhSCAPs.

\section{Neuronal induction}

It was demonstrated that pre-treatment with $10 \mu \mathrm{M}$ of resveratrol for $12 \mathrm{~h}$ actively promoted neural progenitor gene expression. To elucidate the effect of resveratrol on neuronal differentiation of hSCAPs, the cells were pretreated with/without $10 \mu \mathrm{M}$ of resveratrol for $12 \mathrm{~h}$. We hypothesized that RSV-hSCAPs would differentiate into NPCs more than the hSCAPs. The hSCAPs and RSV- 


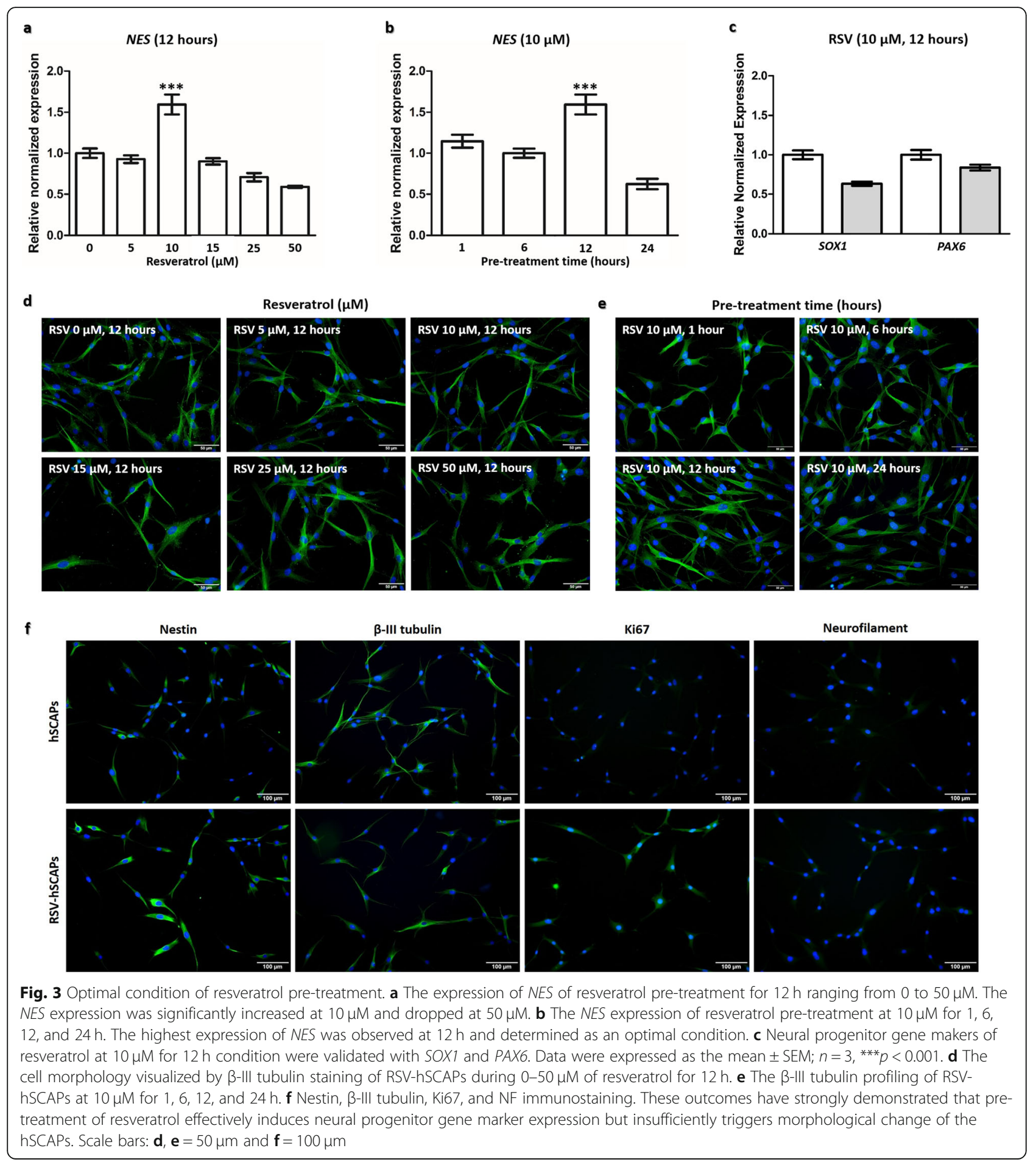

hSCAPs were consequently induced with 2 phases of neuronal induction medium.

The hSCAPs and RSV-hSCAPs were differentiated (d-hSCAPs; Fig. 4a, and RSV-d-hSCAPs; Fig. 4b, respectively) as they showed neuronal-like appearances. Both d-hSCAPs' and RSV-d-hSCAPs' presented several types of neuronal-like morphology, such as round shape, unipolar shape, bipolar shape, multipolar shape, pyramidal shape, and irregular shape. On the other hand, the crt-hSCAPs, which were cultured in the medium without neuronal induction supplements, presented the typical fibroblast and spindle-like shape morphology (Fig. 4c), similar to the primary hSCAPs (Fig. 1a). 


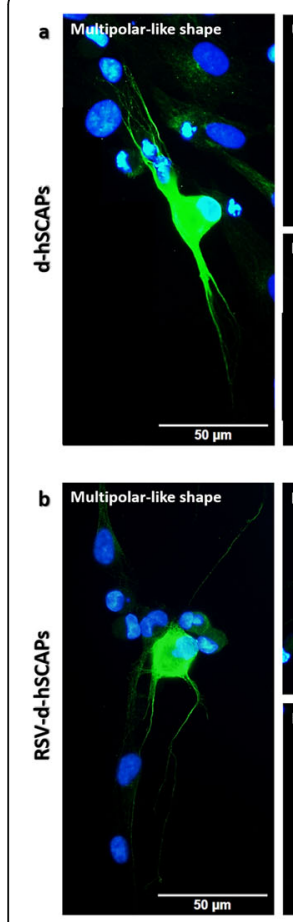

d

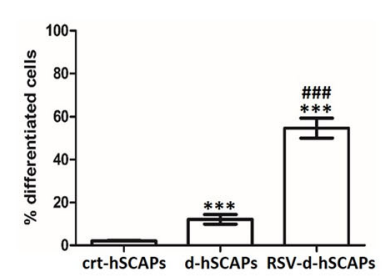

e
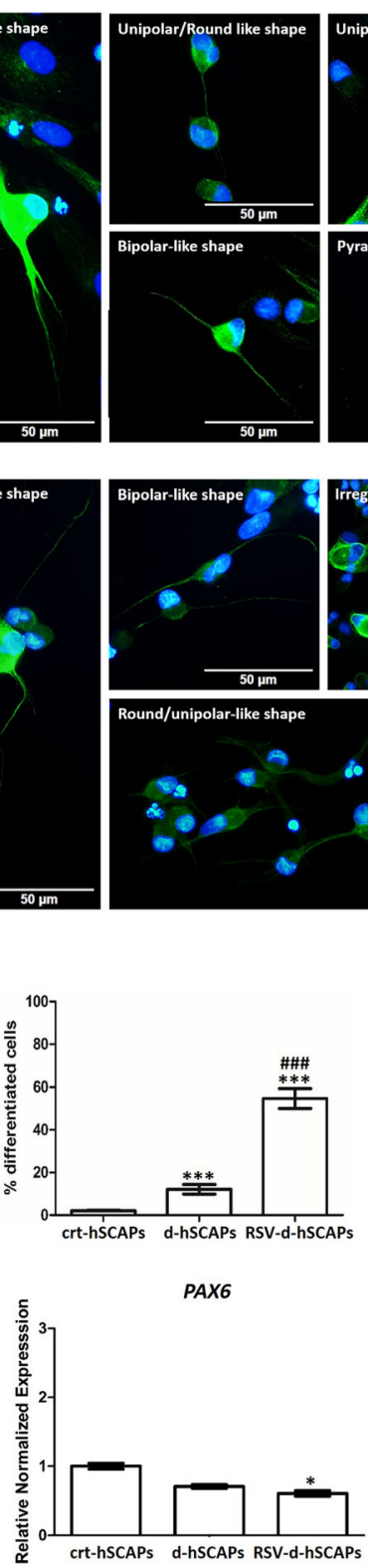
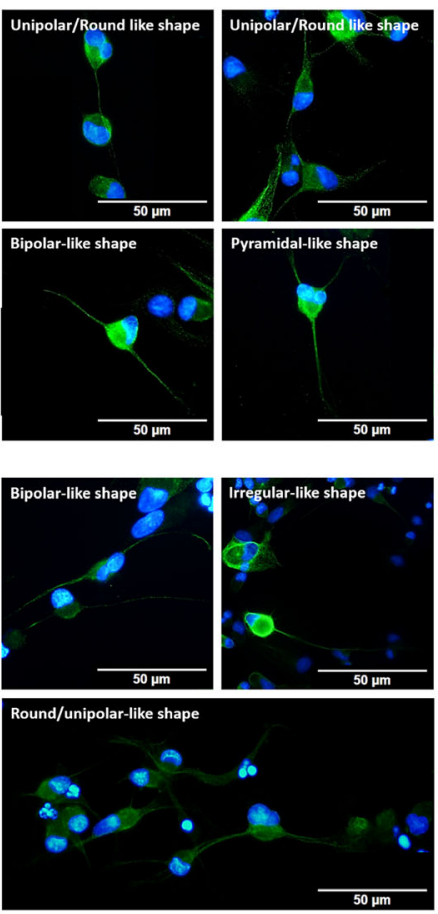

f
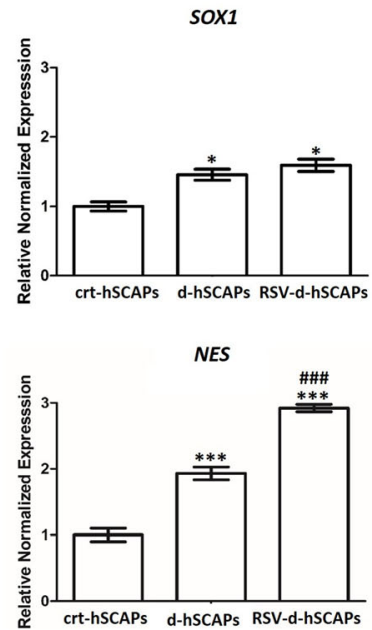
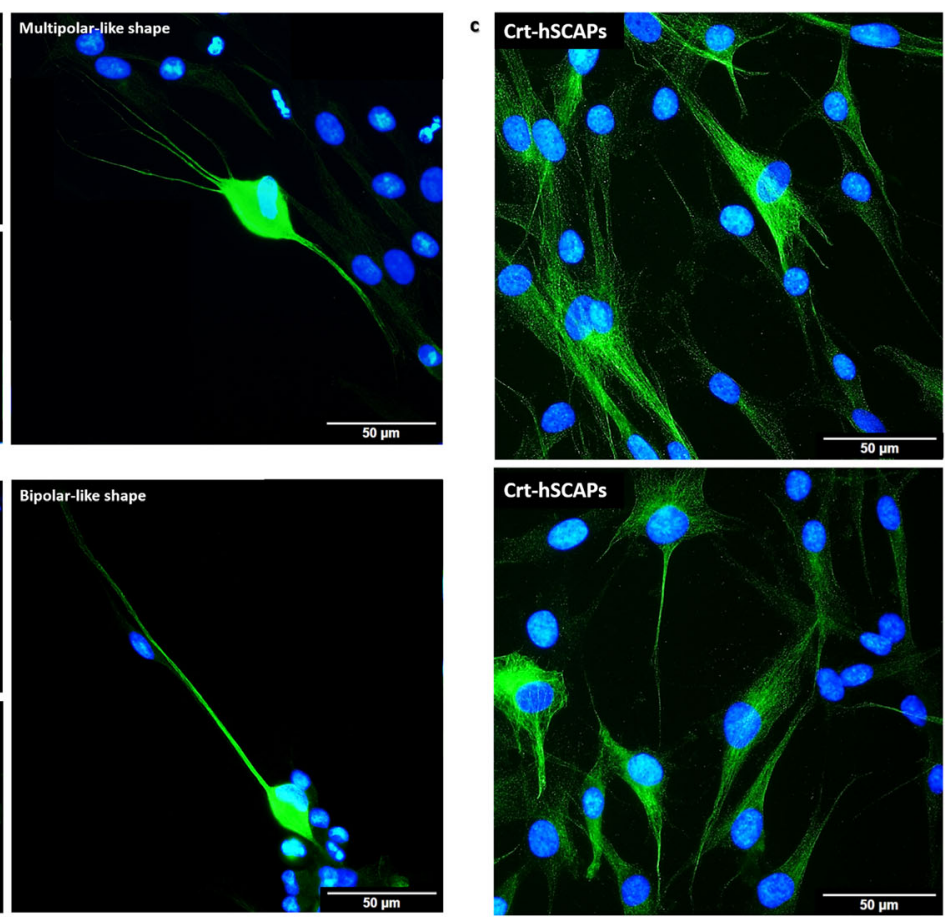

h
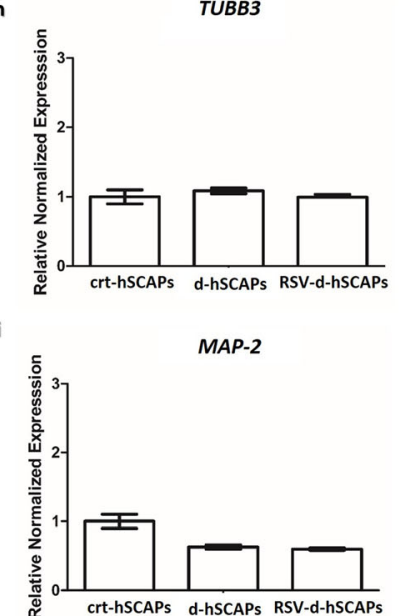

Fig. 4 Neuronal induction. a-c The immunofluorescences profiling ( $\beta$-III tubulin) of crt-hSCAPs, d-hSCAPs, and RSV-d-hSCAPs. These visualizations have revealed that a neuronal induction medium successfully promotes morphological change of d-hSCAPs and RSV-d-hSCAPs into neuronal-like cells, while the crt-hSCAPs still clearly exhibit as fibroblast-like cells. $\mathbf{d}$ The percentage of neuronal differentiation between d-hSCAPs and RSV-dhSCAPs. Resveratrol pre-treatment efficiently enhances the percentage of differentiated cells from $12.11 \pm 5.08$ up to 54.71 \pm 10.39 . Data were expressed as the mean \pm SEM; $n=5,{ }^{* * *} p<0.001$ compared to crt-hSCAPs, ${ }^{\# \#} p<0.001$ compared to d-hSCAPs. e-i The genes expression profiling (PAX6, SOX1, NES, TUBB3, and MAP-2) of crt-hSCAPs, d-hSCAPs, and RSV-d-hSCAPs. Resveratrol pre-treatment synergistically promotes the neural progenitor marker gene; the decreasing expression was expressed in PAX6. The increased expression was highly expressed in SOX1 and NES, but not inTUBB3 or MAP-2. Data were expressed as the mean \pm SEM; $n=3,{ }^{*} p<0.05,{ }^{* * *} p<0.001$ compared to crt-hSCAPs, ${ }^{\# \# \#} p<0.001$ compared to d-hSCAPs. Scale bars: $\mathbf{a}, \mathbf{b}$, and $\mathbf{c}=100 \mu \mathrm{m}$

The percentage of neuronal differentiation of $d$ hSCAPs was $12.11 \pm 5.08 \%$. Interestingly, the neuronal differentiation of RSV-d-hSCAPs was significantly increased to $54.71 \pm 10.39 \%$ (Fig. 4d). Moreover, the RSV-d-hSCAPs demonstrated the lowest expression of PAX6 (Fig. 4e). In contrast, the highest expression of NES and SOX1 was distinctly observed in RSV-d-hSCAPs, as compared to crthSCAPs and d-hSCAPs (Fig. 4f, and Fig. 4g). However, expressions of MAP-2 and TUBB3 genes, which represent late neurogenic and immature postmitotic neuron, were not significantly different between crt- 
hSCAPs, d-hSCAPs, and RSV-d-hSCAPs (Fig. 4h, and Fig. 4i).

\section{Characterization of neuronal cells}

Neuronal cell characteristics were validated by Cresyl violet staining. The Nissl granule as a prominence structure of neurons was observed. Interestingly, the differentiated cells from hSCAPs (Fig. 5b) and RSV-hSCAPs (Fig. 5c) exhibited the neuronal cells appearance and revealed intense purple substance at cell body (white arrow), while the crt-hSCAPs showed the pale purple background of the nucleus (white asterisk) and dark violet of the nucleolus with a typical fibroblast-like shape morphology (Fig. 5a). After neuronal induction, intracellular calcium oscillation was found in differentiated cells to characterize the neurotransmitter releasing activity of neuronal cells (Fig. 5g). Both calcium intensity of dhSCAPs (Fig. 5e) and RSV-d-hSCAPs (Fig. 5f) showed slightly increased and suddenly reached the highest intensity after $2 \mathrm{~min}$. On the other hand, the steady patterns as a baseline intensity were observed at the hSCAPs (Fig. 5d).

\section{Discussion}

Mesenchymal stem cells of dental origin are being considered as a promising source for neurodegenerative therapies due to their self-renewal properties and multipotential differentiation [24]. The hSCAPs derived from a developing root represent a population of early stem cells [7]. Moreover, the hSCAPs have shown the ectomesenchyme origin with migratory neural crest stem cell derivative [25]. Recent studies have demonstrated the characteristics and capacity for multilineage differentiation of hSCAPs [26]. Among the various dental-origin stem cell populations, hSCAPs exhibited superior profiling, including multipotential differentiation, secretion of neurotrophic factors, and neurite outgrowth stimulation [27]. We characterized hSCAPs according to the minimal criteria of MSCs from the International Society for Cellular Therapy (ISCT) [8]. The isolated cells successfully grew on plastic culture vessels and exhibited the typical fibroblast and spindle-shaped morphologies, which represented plastic adherent abilities and the morphology of MSCs. The isolated cells were analyzed for the markers of MSCs. Flow cytometry demonstrated that the cells highly expressed CD73, CD90, CD105, and CD146 but negatively expressed CD34. The cells were able to form colonies that were visualized by Giemsa staining indicating their selfrenewal ability. Moreover, to demonstrate multipotency properties, the isolated cells were induced with osteogenic and adipogenic induction media. The calcified nodule was visualized with Alizarin red, and lipid droplets were clearly stained with Oil Red O. Under neuronal induction, the isolated cells were efficiently differentiated into neuronal-like cells (Figs. 4a, and $5 \mathrm{~b})$. Finally, the isolated cells were positively stained with Nestin to reveal a migratory neural crest derivative of ectomesenchymal origin (Fig. 1d). Taken together, the results verified that the isolated cells established from human apical papilla tissue were MSCs, namely as hSCAPs.

Resveratrol is a non-flavonoid polyphenol compound with a stilbene structure obtained from various plants [18]. Resveratrol has 2 isomeric forms: cis-resveratrol and trans-resveratrol. Importantly, trans-isoform is a stable isoform and is the more predominant common active compound [28], while cis-isoform is unstable and the less common compound. However, the trans-resveratrol can be converted into cis-resveratrol after exposure with heat, UV radiation, or sunlight [29]. Therefore, we freshly prepared the resveratrol solution and maintained it in dark conditions for maximal efficiency. Previous studies have found that resveratrol did not have cytotoxicity on human dental pulp stem cells (hDPSCs) [15] or human bone marrow mesenchymal stem cells (hBMMSCs) [20] at $0-50 \mu \mathrm{M}$ concentrations for $12 \mathrm{~h}$. Some studies reported that the cell viabilities of resveratroltreated human umbilical cord-derived mesenchymal stem cells (hUC-MSCs) did not change at $0-50 \mu \mathrm{M}$ for 24 h [21]. Despite present progress, there are no studies on the cell viability of hSCAPs with different concentrations of resveratrol. In this study, we first demonstrated the cellular toxicity effect of resveratrol on hSCAPs' viability in order to select non-cellular toxic concentrations. The hSCAPs were treated with different concentrations of resveratrol $(0,5,10,15,25,50$, and $100 \mu \mathrm{M})$ for 6,12 , and $24 \mathrm{~h}$, and then the MTT assay was performed. We have clearly shown that the resveratrol treatment did not have a cytotoxic effect on the hSCAPs from 0 to $100 \mu \mathrm{M}$ for $6 \mathrm{~h}, 0-50 \mu \mathrm{M}$ for $12 \mathrm{~h}$, and $0-15 \mu \mathrm{M}$ for 24 $\mathrm{h}$. Additionally, we were firstly reported the $\mathrm{IC}_{50}$ of resveratrol treatment on hSCAPs as $3380 \mathrm{mM}(6 \mathrm{~h})$, $1501 \mu \mathrm{M}(12 \mathrm{~h})$, and $73.33 \mu \mathrm{M}(24 \mathrm{~h})$. The cellular toxicity of resveratrol as explained by the hormetic doseresponse effect lead to positive responses (associated with beneficial effects) at low concentrations and negative responses (associated with toxic effects) at high concentrations [30]. High concentrations of resveratrol promoted insufficient anti-oxidant defense system activities, induced disruption of mitochondrial membrane potential, and increased reactive oxygen species (ROS) production [31]. Furthermore, it was demonstrated that cell viability is dependent upon the duration of resveratrol supplementation. At longer exposure times, increased ROS secretions were observed, which lead to cell death [32]. Therefore, consistent with previous 

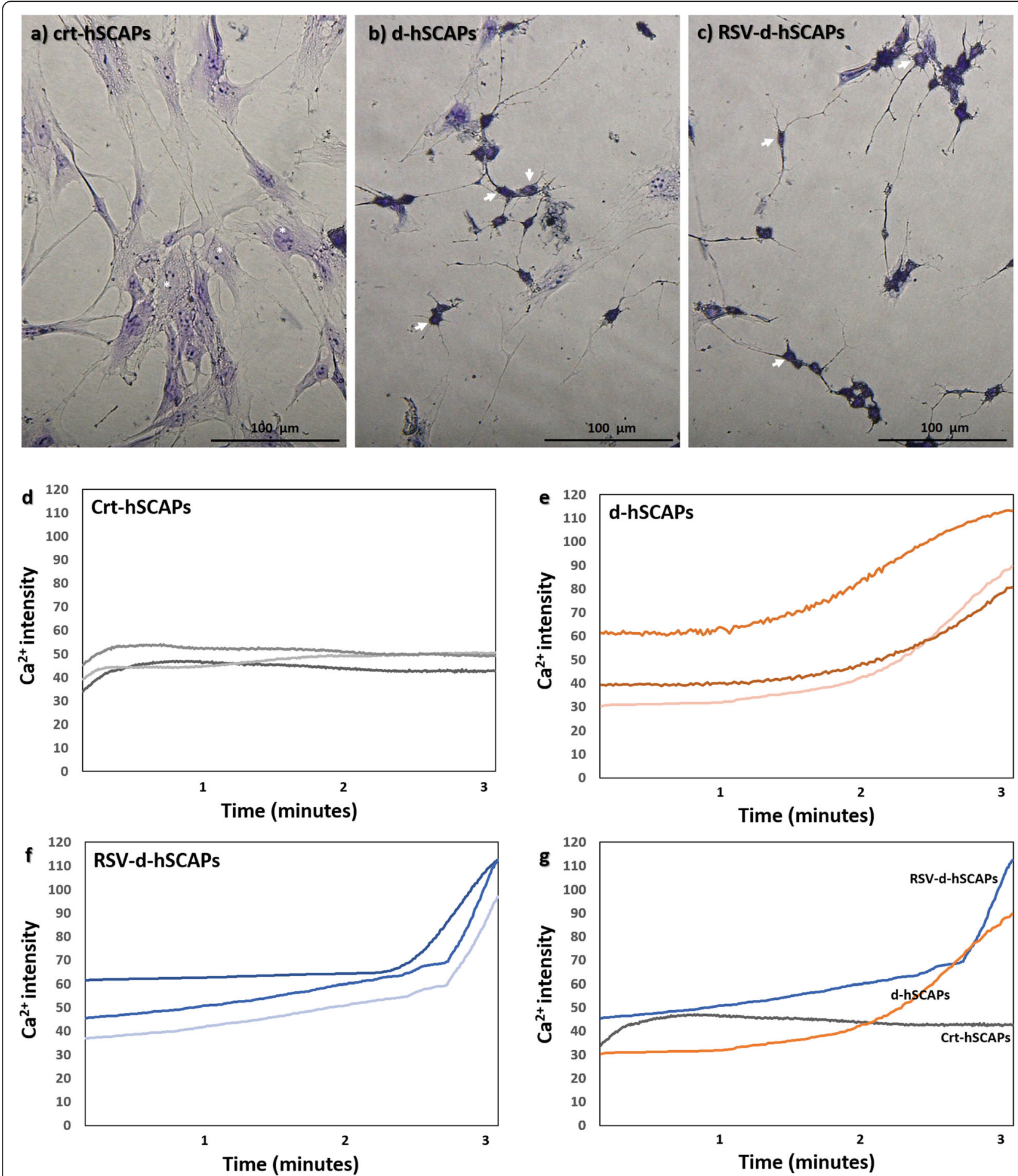

Fig. 5 Characterization of neuronal cells. a-c Characterization of the neuronal cells with Cresyl violet staining. The differentiated cells from hSCAPs and RSV-hSCAPs revealed intense purple substance at cell body (white arrow), while the crt-hSCAPs showed the pale purple background of the nucleus (white asterisk) and dark violet of the nucleolus. Scale bars: $\mathbf{a}, \mathbf{b}$, and $\mathbf{c}=100 \mu \mathrm{m}$. $\mathbf{d}-\mathbf{f}$ The intracellular calcium oscillation of crt-hSCAPs, d-hSCAPs, and RSV-d-hSCAPs. The intensity of calcium has showed to be slightly increased and suddenly reached the highest peak in both d-hSCAPs and RSV-dhSCAPs, while the hSCAPs exhibited steady patterns as a baseline intensity $(n=3)$. $\mathbf{g}$ The graph plotted between $\mathrm{Ca}^{2+}$ intensity and time (minutes) of crt-hSCAPs (gray line), d-hSCAPs (orange line), and RSV-d-hSCAPs (blue line) 
reports, we selected a non-cellular toxicity concentration of resveratrol from 0 to $50 \mu \mathrm{M}$ for $12 \mathrm{~h}$ for further studies.

The optimal condition of resveratrol has effectively induced neuronal-associated gene expression and neuronal differentiation. Previous studies found that the expression of neural progenitor genes were the highest when hBMMSCs were treated with resveratrol at $1 \mu \mathrm{M}$ for $12 \mathrm{~h}$ [20]. Moreover, the treatment of the hDPSCs in $15 \mu \mathrm{M}$ of resveratrol for $12 \mathrm{~h}$ was demonstrated as the optimal condition to induce the expression of NES [15], a gene encoded for Nestin protein which is highly expressed in neural progenitor cells in the subventricular zone of human brain [33]. In this study, we investigated resveratrol-induced neuronal differentiation of the hSCAPs. The characterized hSCAPs were incubated in the range of non-cellular toxicity concentrations of resveratrol $(0-50 \mu \mathrm{M})$ for $12 \mathrm{~h}$ to achieve the highest expression of NES. Then, the concentration of resveratrol that drives the most NES expression was assessed at $1,6,12$, and $24 \mathrm{~h}$ to determine the optimal pre-treatment time. We found that hSCAPs treated with $10 \mu \mathrm{M}$ resveratrol for $12 \mathrm{~h}$ were the optimal condition to enhance NES expression, as revealed by qRT-PCR. To investigate an enrichment of neural progenitor cells genes expression, the RSV-hSCAPs were further accessed genes profiling with $S O X 1$ which was found in neural stem cells in the subventricular zone [33] and PAX6 which uniformly expressed in early neuroectoderm cells [34]. However, the RT-qPCR demonstrated that the expression of these genes was not significantly different compared to control group and consistent with the hSCAPs which were already expressed certain level of NES, suggesting that the treatment $10 \mu \mathrm{M}$ resveratrol for $12 \mathrm{~h}$ specifically enhanced NES expression. These findings correlated with previous studies to select optimal condition of resveratrol with NES expression $[15,20]$. Moreover, the RSV-hSCAPs positively expressed Ki67, suggesting that resveratrol activated proliferative activity. Consistently, $\beta$-III tubulin staining showed that the cell morphology of RSV-hSCAPs was similar to primary hSCAPs, and NF was also negatively expressed (Fig. 3f). These results demonstrated that the RSV-hSCAPs were not differentiated into the neural progenitor cells. However, the optimal conditions of resveratrol which activated NES expression could be more effectively enhanced neuronal differentiation with further neuronal induction medium.

The resveratrol pre-treatment exerts concentrationspecific biphasic responses involving stimulatory and inhibitory dual effects on neuronal progenitor gene expression. Recent studies show that a low concentration $(\geq$ $10 \mu \mathrm{M})$ of resveratrol triggers the TrkA receptors, and consequently phosphorylated SIRT1 and MAPK axis, and cascading downregulation increased CREB-TF (cAMP response element-binding protein transcription factor) involving the neural progenitor gene. On the other hand, higher concentrations $(\geq 20 \mu \mathrm{M})$ of resveratrol inhibited the phosphorylation of TrkA and MAPK, signaling with a result low expression of SIRT1, and neural progenitor gene. Moreover, it also decreased the expression of the anti-apoptotic protein Bcl-2 with parallel increases of activated caspase-3 (hallmark of apoptosis) and $75^{\mathrm{NTR}}$ (death receptor) [35]. Therefore, consistent with previous reports, experiments suggest that the maximal efficiency expression of NES depends on the optimal binding ability between resveratrol ligand and the TrkA receptor, which regrade to the high level of MAPK and SIRT1 downregulation.

To further trigger neuronal differentiation, the hSCAPs and RSV-hSCAPs were synergistically cultured with a neuronal induction medium composed of specific chemical compounds and neurotrophic factors, including $\beta$ mercaptoethanol, DMSO, BHA, and bFGF, which served as extrinsic signaling factors for promoting morphological change and neuronal differentiation [36]. In previous studies, the hBM-MSCs and RSV-hBM-MSCs were differentiated into neuronal-like cells, which exhibited 2 dendrites with longer than $60 \mu \mathrm{m}$ under a neuronal induction medium and positively expressed neurofilament protein. The high rate of neuronal differentiation was demonstrated from the RSV-dhBM-MSCs [20]. Moreover, the differentiated cells derived from hDPSCs and RSV-hDPSCs (d-hDPSCs and RSV-dhDPSCs) had significantly increased neuronal-specific marker genes, including NES, MSI1, and NF-M, which indicated that the RSV-d-hDPSCs were superior for neuronal differentiation profiling [15]. In this study, we have demonstrated that synergistically neuronal induction medium induced hSCAPs and RSV-hSCAPs into differentiated cells. Firstly, the differentiated cells derived from hSCAPs and RSV-hSCAPs (d-hSCAPs and RSV-d-hSCAPs) were exhibit neuronal-like morphology in several types, including round shape, unipolar shape, bipolar shape, multipolar shape, irregular shape, and pyramidal shape (Figs. 4a, b) with $\beta$-III tubulin positive staining, whereas the crt-hSCAPs, which were cultured with a basal medium, presented a flattened shaped (Fig. 4c) as did the primary hSCAPs. Secondly, our study also demonstrated that both d-hSCAPs and RSV-dhSCAPs revealed intense purple granule of Nissl substance, a hallmark of neurons [37], at cell body, while the crt-hSCAPs showed the dark violet of nucleolus in pale purple background of the nucleus, suggesting that the d-hSCAPs and RSV-d-hSCAPs were characterized as neuronal cells. Interestingly, resveratrol pre-treatment effectively enhances neuronal differentiation. The percentage of differentiated cells was significantly increased from $12.11 \pm 5.08$ (d-hSCAPs) to up to $54.71 \pm 10.39$ (RSV-d-hSCAPs).

Neuronal-specific marker genes expression was evaluated to confirm the neural progenitor cells. A recent study demonstrated that the neural progenitor cells 
derived from hDPSCs were insufficiently expressed of PAX6. Taken together, highly expressed NES and SOX1 and weakly expressed $P A X 6$ profiling are used as early stage markers of neuronal differentiation [38]. Moreover, a previous study has shown the neuronal differentiation potential of hSCAPs. The differentiated cells derived from hSCAPs exhibited neuronal-like cell morphology under long-term neuronal induction for 5 weeks. However, the qRT-PCR has revealed that the differentiated cells were highly expressed NSE and weakly detected in TUBB3 and NF-M. This evidence suggests that the hSCAPs are more restricted and committed in their neuronal differentiation at an early stage [38]. Our results provided 2 sequential phases of neuronal induction; the differentiated cells presented that the increasing expression was only observed in NES and SOX1 but not in PAX6 and MAP-2 or TUBB3 in d-hSCAPs, as revealed by qRT-PCR. Our results were consistent with the previous study, which strongly confirmed that our differentiated cells were characterized as neural progenitor cells. Importantly, we have found that the synergistic pretreatment resveratrol with neuronal induction medium triggered differentiation into neural progenitor-like cells with specific expressions of NES and SOX1 and showed a higher percentage of neuronal differentiation than $d$ hSCAPs by 4 times.

Recent approaches have been defined parameters to evaluate in vitro induced neurons [39]. First are structural appearances that included cytoskeletal proteins. The differentiated cells exhibited a neuronal shape which positively detected neural cytoskeletal proteins such as $\beta$-III tubulin and neurofilament $[12,13,20]$ or neuronal cell-specific markers such as Nestin, CD133, glial fibrillary acid protein (GFAP), MAP-2, enolase, and synaptophysin $[11,15,20,21]$. Second are functional characteristics involving functional neuronal networks, intercellular communication [40, 41], and intracellular signaling cascades $[12,23]$. Calcium ions are internalized into neurons to modulate vesicular neurotransmitter releasing [42]. Intracellular calcium activity has been used to represent neuronal activity as it closely correlated with electrical activity recorded from whole-cell patchclamp [43]. In this study, we have observed intracellular calcium oscillation to prove functionality of differentiated cells. We use Fluo-3 as an indicator to detect dynamics of intracellular calcium signaling during neurotransmitter transmission [44]. Previously, the neuronal cell-derived human cord blood mesenchymal stem cells which are triggered by the combination between resveratrol and nerve growth factor for 4 days demonstrated the increasing of intracellular $\mathrm{Ca}^{2+}$ level in a time-dependent manner [12]. Our study showed a slightly increasing pattern of calcium intensity in dhSCAPs and RSV-d-hSCAPs, while the steady patterns as a baseline intensity were observed only in hSCAPs suggesting that the d-hSCAPs and RSV-d-hSCAPs were confirmed as functional neuronal cells.

The application of resveratrol to mesenchymal stem cell-based regenerative medicine has been demonstrated in various in vitro bioactivities, including self-renewal, multipotency [45], senescence [21], cell aging [46], osteogenic differentiation [47], adipogenic differentiation [48], and neuronal differentiation [12]. Importantly, in vitro models have the potential to demonstrate insight into cellular and molecular mechanisms. Moreover, reduction of animal use and increasing time- and costeffectiveness were undertaken on in vitro model [49]. The potential effects of resveratrol are triggered by SIRT1 activation. The SIRT1 acts as the central modulator of bioactivities signaling pathways [50]. Resveratrol indirectly activates SIRT1 by increasing intracellular cAMP following the inhibition of cAMP-dependent phosphodiesterase (PDE) [51]. SIRT1 strongly promotes neuronal differentiation through PKA/GSK3- $\beta / \beta$-catenin and PKA/ERK1/2 axis [12]. SIRT1 also plays important roles in controlling microtubule dynamics and neurite outgrowth stimulation during axon elongation by deacetylating AKT [52]. Taken together, previous studies confirm the potential effect of resveratrol, through SIRT1 activation, on neuronal differentiation by changing the structural features of the cell into neuronal phenotype.

Moreover, resveratrol has an efficiently therapeutic effect on in vivo models, including enhancing liver regeneration [53] and cardiogenic differentiation in cardiomyopathy [54]. Interestingly, oral administration of trans-resveratrol $20 \mathrm{mg} /$ $\mathrm{kg}$ body weight for 45 days into aged rat has recovered the number of newly generated neurons in the hippocampus with positive Nissl substance and BrdU (proliferative marker) labeling [35]. Additionally, resveratrol treatment improved learning and memory and enhanced neurogenesis in Alzheimer's disease $(\mathrm{AD})$ mouse model [55]. However, the transplantation of resveratrol-treated hSCAPs or NPCs derived from hSCAPs into animal model of neurodegenerative disease needs to be performed in future studies to reflect the correlation of potential effects of resveratrol on neuronal differentiation between in vitro and in vivo models.

Taken together, we have demonstrated that resveratrol serves as an effective enhancer of neuronal differentiation by promoting neural progenitor gene expression in the hSCAPs and that the RSV-hSCAPs are more differentiated into neuronal-like cells at the early stage than at the late stage in a neuronal induction medium. These results suggest that a resveratrol pre-treatment of MSCs may be an effective alternative approach for neurodegenerative disease.

\section{Conclusion}

This study demonstrated the capacity of hSCAPs for neuronal differentiation and that pre-treatment with 
resveratrol efficiently induces neural progenitor marker gene expression, which synergistically enhances neural progenitor-like cell induction within a neuronal induction medium. Thus, these findings suggest the alternative of using hSCAPs and the potential of resveratrol treatment as a stem cell-based therapy, for further transplantation in the treatment of neurodegenerative disease.

\section{Abbreviations}

A570-A690: Absorbance at $570 \mathrm{~nm}$ minus $690 \mathrm{~nm}$; AD: Alzheimer's disease; AKT: Protein kinase B; bFGF: Basic fibroblast growth factor; BHA: Butylated hydroxyanisole; CAMP: Cyclic adenosine monophosphate; CD: Cluster of differentiation; CNS: Central nervous system; Crt-hSCAPs: Control hSCAPs; dhBM-MSCs: Differentiated cell-derived human bone marrow mesenchymal stem cells; d-hDPSCs: Differentiated cell-derived human dental pulp stem cells; d-hSCAPs: Differentiated cell-derived human stem cells from apical papilla; DMEM/F-12: Dulbecco's Modified Eagle Medium: Nutrient Mixture $F^{-12}$ (Ham); DMSO: Dimethyl sulfoxide; DSCs: Dental-derived stem cells; ERK1/ 2: Extracellular signaling regulated kinase1/2; FBS: Fetal bovine serum; GAPD H: Glyceraldehyde 3-phosphate dehydrogenase; GFAP: Glial fibrillary acid protein; GSK3- $\beta$ : Glycogen synthase kinase 3- $\beta$; hBM-MSCs: Human bone marrow-derived mesenchymal stem cells; hDPSCs: Human dental pulp stem cells; hSCAPs: Human stem cells from apical papilla; hUC-MSCs: Human umbilical cord-derived mesenchymal stem cells; IBMX: 3-Isobutyl-1methylxanthine; $I_{50}$ : 50\% inhibitory concentration; ISCT: International Society for Cellular Therapy; MAP-2: Microtubule associated protein-2; MSCs: Mesenchymal stem cells; MTT: Methylthiazolyldiphenyl-tetrazolium bromide; NF: Neurofilaments; NF-M: Neurofilament medium-type; NPCs: Neural progenitor cells; NES: Human gene encoded for Nestin protein; PDE: Phosphodiesterase; PKA: Protein kinase A; qRT-PCR: Quantitative realtime polymerase chain reaction; RSV: Resveratrol; RSV-d-hBM-

MSCs: Differentiated cell-derived resveratrol pre-treated hBM-MSCs; RSV-dhDPSCs: Differentiated cell-derived resveratrol pre-treated hDPSCs; RSV-dhSCAPs: Differentiated cell-derived resveratrol pre-treated hSCAPs; RSVhSCAPs: Resveratrol pre-treated hSCAPs at optimal condition; SEM: Standard error of mean; SIRT1: Sirtuin 1; TrkA: Tyrosine kinase receptor type 1; aMEM: Alpha Minimum Essential Medium

\section{Acknowledgements}

The authors would like to thank Miss. Ratchaporn Srichan and Miss. Supaporn Mala at Oral Tissue, Cells and Molecular Biology Analysis and Research Center, Faculty of Dentistry, Mahidol University for technical assistance, Olympus Bioimaging Center (OBC), Faculty of Science, Mahidol University, Thailand for cell imaging, and Michael Helgeson for the English language review. The Ki67: hybridoma, monoclonal antibody developed by EU Program Affinomics (EMBL MACF) and neurofilaments: hybridoma, monoclonal antibody developed by Gilbert, W./Stainier, D. (Max Planck Institute for Heart \& Lung Research) were obtained from the Developmental Studies Hybridoma Bank, created by the NICHD of the NIH and maintained at The University of lowa, Department of Biology, lowa City, IA 52242.

\section{Authors' contributions}

AS contributed to the experimental conceptualization and design, performed all the experiments, analyzed and interpreted the data, and wrote the manuscript. TG analyzed and interpreted the data and provided considerable manuscript review. NR contributed to the experimental conceptualization and design, provided collection and isolation of hSCAPs, contributed human ethical considerations and revision of work, and provided considerable manuscript review. CP assisted in the characterization of hSCAPs and gene expression analysis. CT contributed to the experimental conceptualization and design, considerable manuscript review, supervision of work, and manuscript development. All authors read and approved the final manuscript.

\section{Funding}

This work was supported by grants obtained from Science Achievement Scholarship of Thailand (SAST), partially supported by Central Instrument Facilities (CIF) Faculty of Science, Mahidol University, Thailand.

\section{Availability of data and materials}

Not applicable

\section{Ethics approval and consent to participate}

This study was approved by the Ethics Committee on Human Rights Related to Human Experimentation of Faculty of Dentistry/Faculty of Pharmacy, Mahidol University, Thailand (COE. No. MU-DT/PY-IRB 2019/027.2405); project number: 2019/DT068. The procedure was conducted in accordance with the Declaration of Helsinki. Written informed consent was obtained prior to inclusion in the study.

\section{Consent for publication}

Not applicable

\section{Competing interests}

The authors declare that they have no competing interests.

\section{Author details}

'Department of Anatomy, Faculty of Science, Mahidol University, 272 RAMA VI Road, Ratchathewi, Bangkok 10400, Thailand. ${ }^{2}$ Chakri Naruebodindra Medical Institute, Faculty of Medicine Ramathibodi Hospital, Mahidol University, 111 Bang Pla, Bang Phli, Samut Prakan 10540, Thailand. ${ }^{3}$ Department of Pharmacology, Faculty of Dentistry, Mahidol University, 6 Yothi Road, Ratchathewi, Bangkok 10400, Thailand.

Received: 14 May 2020 Accepted: 2 December 2020

Published online: 14 December 2020

\section{References}

1. Dua T, M Cumbrera, C Mathers and S Saxena. Global burden of neurological disorders: estimates and projections. Neurological Disorders: Public Health Challenges. In: Campanini B, editors. Geneva: World Health Organization; 2006. p. 27-40.

2. Björklund A, Lindvall O. Cell replacement therapies for central nervous system disorders. Nat Neurosci. 2000;3(6):537-44.

3. Eriksson PS, Perfilieva E, Björk-Eriksson T, Alborn AM, Nordborg C, Peterson DA, Gage FH. Neurogenesis in the adult human hippocampus. Nat Med. 1998:4(11):1313-7.

4. Arvidsson A, Collin T, Kirik D, Kokaia Z, Lindvall O. Neuronal replacement from endogenous precursors in the adult brain after stroke. Nat Med. 2002; 8(9):963-70.

5. Sonoyama W, Liu Y, Yamaza T, Tuan RS, Wang S, Shi S, Huang GT. Characterization of the apical papilla and its residing stem cells from human immature permanent teeth: a pilot study. J Endod. 2008;34(2):166-71.

6. Huang GT, Sonoyama W, Liu Y, Liu H, Wang S, Shi S. The hidden treasure in apical papilla: the potential role in pulp/dentin regeneration and bioroot engineering. J Endod. 2008;34(6):645-51.

7. Huang GT, Gronthos S, Shi S. Mesenchymal stem cells derived from dental tissues vs. those from other sources: their biology and role in regenerative medicine. J Dent Res. 2009;88(9):792-806.

8. Dominici M, Le Blanc K, Mueller I, Slaper-Cortenbach I, Marini F, Krause D, et al. Minimal criteria for defining multipotent mesenchymal stromal cells. Int Soc Cell Ther Position Statement. 2006;8(4):315-7.

9. Anghileri E, Marconi S, Pignatelli A, Cifelli P, Galié M, Sbarbati A, Krampera M, Belluzzi O, Bonetti B. Neuronal differentiation potential of humanadipose-derived mesenchymal stem cells. Stem Cells Dev. 2008;17(5): 909-16.

10. Jeong S-G, Ohn T, Kim SH, Cho G-W. Valproic acid promotes neuronal differentiation by induction of neuroprogenitors in human bone-marrow mesenchymal stromal cells. Neurosci Lett. 2013;554:22-7.

11. Guo L, Wang L, Wang L, Yun-Peng S, Zhou JJ, Zhao Z, Li DP. Resveratrol Induces Differentiation of Human Umbilical Cord Mesenchymal Stem Cells into Neuron-Like Cells. Stem Cells Int. 2017;2017:1651325.

12. Jahan $S$, Singh $S$, Srivastava A, Kumar V, Kumar D, Pandey A, Rajpurohit CS, Purohit AR, Khanna VK, Pant AB. PKA-GSK3 $\beta$ and $\beta$-Catenin Signaling Play a Critical Role in Trans-Resveratrol Mediated Neuronal Differentiation in Human Cord Blood Stem Cells. Mol Neurobiol. 2018;55(4):2828-39. https:// doi.org/10.1155/2017/1651325.

13. Bueno C, Martínez-Morga M, Martínez S. Non-proliferative neurogenesis in human periodontal ligament stem cells. Sci Rep. 2019;9(1):1-17. 
14. Gonmanee T, Thonabulsombat C, Vongsavan $\mathrm{K}$, Sritanaudomchai H. Differentiation of stem cells from human deciduous and permanent teeth into spiral ganglion neuron-like cells. Arch Oral Biol. 2018;88:34-41.

15. Geng YW, Zhang Z, Liu MY, Hu WP. Differentiation of human dental pulp stem cells into neuronal by resveratrol. Cell Biol Int. 2017;41(12):1391-8.

16. Fan W, Cheng K, Qin X, Narsinh KH, Wang S, Hu S, et al. mTORC1 and mTORC2 play different roles in the functional survival of transplanted adipose-derived stromal cells in hind limb ischemic mice via regulating inflammation in vivo. Stem Cells. 2013;31(1):203-14.

17. An J, Chen B, Wang A, Hao D, Zhang Q, Zhao J, et al. Modulatory effects of natural products on neuronal differentiation. 2018.

18. Ramprasath VR, Jones PJ. Anti-atherogenic effects of resveratrol. Eur J Clin Nutr. 2010;64(7):660-8.

19. Pallàs M, Casadesús G, Smith MA, Coto-Montes A, Pelegri C, Vilaplana J, Camins A. Resveratrol and neurodegenerative diseases: activation of SIRT1 as the potential pathway towards neuroprotection. Curr Neurovasc Res. 2009:6(1):70-81.

20. Joe IS, Jeong SG, Cho GW. Resveratrol-induced SIRT1 activation promotes neuronal differentiation of human bone marrow mesenchymal stem cells. Neurosci Lett. 2015;584:97-102.

21. Wang X, Ma S, Meng N, Yao N, Zhang K, Li Q, et al. Resveratrol exerts dosage-dependent effects on the self-renewal and neural differentiation of hUC-MSCs. Mol Cells. 2016;39(5):418.

22. Livak KJ, Schmittgen TD. Analysis of relative gene expression data using real-time quantitative $P C R$ and the $2-\Delta \Delta C T$ method. Methods. 2001;25(4): 402-8.

23. Gonmanee $T$, Sritanaudomchai $H$, Vongsavan $K$, Faisaikarm T, Songsaad A, White $\mathrm{KL}$, et al. Neuronal differentiation of dental pulp stem cells from human permanent and deciduous teeth following coculture with rat auditory brainstem slices. Anat Rec. 2020;303(11):2931-46.

24. Varga G, Gerber G. Mesenchymal stem cells of dental origin as promising tools for neuroregeneration. Stem Cell Res Ther. 2014;5(2):61.

25. Green SA, Simoes-Costa M, Bronner ME. Evolution of vertebrates as viewed from the crest. Nature. 2015;520(7548):474-82.

26. Simonovic J, Toljic B, Nikolic N, Peric M, Vujin J, Panajotovic R, et al. Differentiation of stem cells from apical papilla into neural lineage using graphene dispersion and single walled carbon nanotubes. J Biomed Mater Res A. 2018;106(10):2653-61.

27. Kolar MK, Itte VN, Kingham PJ, Novikov LN, Wiberg M, Kelk P. The neurotrophic effects of different human dental mesenchymal stem cells. Sci Rep. 2017;7(1):12605.

28. Weiskirchen S, Weiskirchen R. Resveratrol: how much wine do you have to drink to stay healthy? Adv Nutr. 2016;7(4):706-18.

29. Camont L, Cottart C-H, Rhayem Y, Nivet-Antoine V, Djelidi R, Collin F, et al. Simple spectrophotometric assessment of the trans-/cis-resveratrol ratio in aqueous solutions. Anal Chim Acta. 2009;634(1):121-8.

30. Calabrese EJ, Mattson MP, Calabrese V. Resveratrol commonly displays hormesis: occurrence and biomedical significance. Hum Exp Toxicol. 2010; 29(12):980-1015.

31. Posadino AM, Giordo R, Cossu A, Nasrallah GK, Shaito A, Abou-Saleh H, et al. Flavin oxidase-induced ROS generation modulates PKC biphasic effect of resveratrol on endothelial cell survival. Biomolecules. 2019;9(6):209.

32. Martins LAM, Coelho BP, Behr G, Pettenuzzo LF, Souza IC, Moreira JCF, et al. Resveratrol induces pro-oxidant effects and time-dependent resistance to cytotoxicity in activated hepatic stellate cells. Cell Biochem Biophys. 2014; 68(2):247-57.

33. Namiki J, Suzuki S, Masuda T, Ishihama $Y$, Okano H. Nestin protein is phosphorylated in adult neural stem/progenitor cells and not endothelial progenitor cells. Stem Cells Int. 2012;2012:430138.

34. Zhang X, Huang CT, Chen J, Pankratz MT, Xi J, Li J, et al. Pax6 is a human neuroectoderm cell fate determinant. Cell Stem Cell. 2010;7(1):90-100

35. Kumar V, Pandey A, Jahan S, Shukla RK, Kumar D, Srivastava A, et al. Differential responses of trans-resveratrol on proliferation of neural progenitor cells and aged rat hippocampal neurogenesis. Sci Rep. 2016;6: 28142.

36. Sanchez-Ramos J, Song S, Cardozo-Pelaez F, Hazzi C, Stedeford T, Willing A, et al. Adult bone marrow stromal cells differentiate into neural cells in vitro. Exp Neurol. 2000;164(2):247-56

37. Wilkinson JL. Neurons and Neuroglia. In: Wilkinson JL, editors. Neuroanatomy for Medical Students (Second Editions): ButterworthHeinemann. Oxford, 1992. p. 20-31.
38. Li D, Zou X-Y, El-Ayachi I, Romero LO, Yu Z, Iglesias-Linares A, et al. Human dental pulp stem cells and gingival mesenchymal stem cells display action potential capacity in vitro after neuronogenic differentiation. Stem Cell Rev Rep. 2019;15(1):67-81.

39. de Groot MW, Westerink RH, Dingemans MM. Don't judge a neuron only by its cover: neuronal function in in vitro developmental neurotoxicity testing. Toxicol Sci. 2013;132(1):1-7.

40. Gervois P, Struys T, Hilkens P, Bronckaers A, Ratajczak J, Politis C, Brône B, Lambrichts I, Martens W. Neurogenic maturation of human dental pulp stem cells following neurosphere generation induces morphological and electrophysiological characteristics of functional neurons. Stem Cells Dev. 2015;24(3):296-311.

41. Ullah I, Subbarao RB, Kim E-J, Bharti D, Jang S-J, Park J-S, et al. In vitro comparative analysis of human dental stem cells from a single donor and its neuronal differentiation potential evaluated by electrophysiology. Life Sci. 2016;154:39-51.

42. Neher $E$, Sakaba T. Multiple roles of calcium ions in the regulation of neurotransmitter release. Neuron. 2008;59(6):861-72.

43. Rochefort NL, Garaschuk O, Milos R-I, Narushima M, Marandi N, Pichler B, et al. Sparsification of neuronal activity in the visual cortex at eye-opening. Proc Natl Acad Sci. 2009;106(35):15049-54.

44. Marambaud P, Dreses-Werringloer U, Vingtdeux V. Calcium signaling in neurodegeneration. Mol Neurodegener. 2009;4(1):1-15.

45. Yoon DS, Choi Y, Choi SM, Park KH, Lee JW. Different effects of resveratrol on early and late passage mesenchymal stem cells through $\beta$-catenin regulation. Biochem Biophys Res Commun. 2015;467(4):1026-32.

46. Kornienko JS, Smirnova I, Pugovkina N, Ivanova JS, Shilina M, Grinchuk T, et al. High doses of synthetic antioxidants induce premature senescence in cultivated mesenchymal stem cells. Sci Rep. 2019;9(1):1-13.

47. Song LH, Pan W, Yu YH, Quarles LD, Zhou HH, Xiao ZS. Resveratrol prevents CsA inhibition of proliferation and osteoblastic differentiation of mouse bone marrow-derived mesenchymal stem cells through an ER/NO/cGMP pathway. Toxicol in Vitro. 2006;20(6):915-22.

48. Caldarelli I, Speranza MC, Bencivenga D, Tramontano A, Borgia A, Pirozzi AVA, et al. Resveratrol mimics insulin activity in the adipogenic commitment of human bone marrow mesenchymal stromal cells. Int J Biochem Cell Biol. 2015:60:60-72.

49. Lein $P$, Locke $P$, Goldberg A. Meeting report: alternatives for developmental neurotoxicity testing. Environ Health Perspect. 2007;115(5):764-8.

50. Donmez $\mathrm{G}$. The neurobiology of sirtuins and their role in neurodegeneration. Trends Pharmacol Sci. 2012;33(9):494-501.

51. Park SJ, Ahmad F, Philp A, Baar K, Williams T, Luo H, Ke H, Rehmann H, Taussig R, Brown AL, Kim MK, Beaven MA, Burgin AB, Manganiello V, Chung $\mathrm{JH}$. Resveratrol ameliorates aging-related metabolic phenotypes by inhibiting CAMP phosphodiesterases. Cell. 2012;148(3):421-33.

52. Li XH, Chen C, Tu Y, Sun HT, Zhao ML, Cheng SX, Qu Y, Zhang S. Sirt1 promotes axonogenesis by deacetylation of Akt and inactivation of GSK3. Mol Neurobiol. 2013;48(3):490-9.

53. Okay E, Simsek T, Subasi C, Gunes A, Duruksu G, Gurbuz Y, et al. Cross effects of resveratrol and mesenchymal stem cells on liver regeneration and homing in partially hepatectomized rats. Stem Cell Rev Rep. 2015;11(2):322-31.

54. Pınarlı FA, Turan NN, Güçlü Pınarlı F, Okur A, Sönmez D, Ulus T, et al. Resveratrol and adipose-derived mesenchymal stem cells are effective in the prevention and treatment of doxorubicin cardiotoxicity in rats. Pediatr Hematol Oncol. 2013;30(3):226-38.

55. Wang X, Ma S, Yang B, Huang T, Meng N, Xu L, et al. Resveratrol promotes hUC-MSCs engraftment and neural repair in a mouse model of Alzheimer's disease. Behav Brain Res. 2018;339:297-304.

\section{Publisher's Note}

Springer Nature remains neutral with regard to jurisdictional claims in published maps and institutional affiliations. 